\title{
Neonatal mortality among neonates admitted to NICU of Hiwot Fana specialized university hospital, eastern Ethiopia, 2020: a cross-sectional study design
}

Addis Eyeberu ${ }^{1 *}$, Hirpo Shore ${ }^{2}$, Tamirat Getachew ${ }^{1}$, Genanaw Atnafe ${ }^{3}$ and Merga Dheresa ${ }^{4}$

\begin{abstract}
Background: In Ethiopia, neonatal mortality is unacceptably high. Despite many efforts made by the government and other partners to reduce neonatal mortality; it has been increasing since 2014. Factors associated with neonatal mortality were explained by different researchers indifferently. There is no clear evidence to identify the magnitude of neonatal mortality and associated factors in the study area. The study aimed to assess the magnitude and factors associated with neonatal mortality.
\end{abstract}

Methods: Facility-based cross-sectional study was conducted among 834 randomly selected neonates. The study was conducted from February 20 to March 21, 2020. Data were extracted from medical records using a checklist adapted from the World Health Organization, and neonatal registration book. The data were inserted into Epi-data version 3.1 and then exported into SPSS window version 20 for analysis. Bivariate and multivariate analyses were employed to identify the association between independent variables and the outcome variable.

Results: Magnitude of neonatal mortality was 14.4\% (95\% Cl:11.9,16.7). Being neonates of mothers whose pregnancy was complicated with antepartum hemorrhage $[A O R=4.13,95 \% \mathrm{Cl}:(1.92,8.85)]$, born from mothers with current pregnancy complicated with pregnancy-induced hypertension $[\mathrm{AOR}=4.41,95 \% \mathrm{Cl}:(1.97,9.86)]$, neonates of mothers with multiple pregnancy $[\mathrm{AOR}=2.87,95 \% \mathrm{Cl}(1.08,7.61)]$, neonates delivered at the health center $[\mathrm{AOR}=$ 5.05, 95\%Cl: $(1.72,14.79)]$, low birth weight $[\mathrm{AOR}=4.01,95 \% \mathrm{Cl}(1.30,12.33)]$, having perinatal asphyxia $[\mathrm{AOR}=3.85$, 95\%Cl: $(1.83,8.10)]$, and having early-onset neonatal sepsis [AOR $=3.93,95 \% \mathrm{Cl}:(1.84,8.41)]$ were factors significantly associated with neonatal mortality.

\footnotetext{
* Correspondence: addiseyeberu@gmail.com

'Department of Midwifery, School of Nursing and Midwifery, College of

Health and Medical Sciences, Haramaya University, P.O. BOX 138, Dire Dawa, Harar, Ethiopia

Full list of author information is available at the end of the article
}

(C) The Author(s). 2021 Open Access This article is licensed under a Creative Commons Attribution 4.0 International License, which permits use, sharing, adaptation, distribution and reproduction in any medium or format, as long as you give appropriate credit to the original author(s) and the source, provide a link to the Creative Commons licence, and indicate if changes were made. The images or other third party material in this article are included in the article's Creative Commons licence, unless indicated otherwise in a credit line to the material. If material is not included in the article's Creative Commons licence and your intended use is not permitted by statutory regulation or exceeds the permitted use, you will need to obtain permission directly from the copyright holder. To view a copy of this licence, visit http://creativecommons.org/licenses/by/4.0/ The Creative Commons Public Domain Dedication waiver (http://creativecommons.org/publicdomain/zero/1.0/) applies to the data made available in this article, unless otherwise stated in a credit line to the data. 


\begin{abstract}
(Continued from previous page)
Conclusion: The proportion of neonatal mortality was relatively in line with other studies but still needs attention.

Antepartum hemorrhage, Pregnancy-induced hypertension, place of delivery, low birth weight, having perinatal asphyxia, and having neonatal sepsis were independent factors. The hospital, and health care workers should give attention to neonates admitted to intensive care units by strengthening the quality of care given at neonatal intensive care unit like infection prevention and strengthening early detection and treatment of health problems during Antenatal care visit.
\end{abstract}

Keywords: Neonatal mortality, NICU, Newborn

\section{Introduction}

Neonatal death is the death of a newborn in the first 4 weeks of life [33]. Even though there are some variations on causes of neonatal death, the three major causes of neonatal death are infections, prematurity, and birth asphyxia [26].

Globally, 2.5 million neonates died in 2018. Between 2018 and 2030, it is estimated that 27.8 million neonates will die if each country maintains its current rate of reduction in neonatal mortality rate (NMR) [12]. SubSaharan Africa had the highest neonatal mortality rate with 28 deaths per 1000 live births in 2018. This is one of the regions with the least progress, accounting for $38 \%$ of neonatal deaths in the world. Despite the $18.3 \%$ annual reduction rate of the average neonatal mortality from 1990 to 2018 in sub-Saharan Africa, the number of neonatal deaths remains around 1 million deaths per year due to an increasing number of births [12, 27, 28].

In Ethiopia; neonatal mortality was reduced from 39 deaths per 1000 live birth in 2005 to 28 death per 1000 live birth in 2014. However, the current report indicates an increment in neonatal mortality from 28 death per 1000 live birth in 2014 to 30 neonatal death per 1000 live birth in 2019 [6]. More than four-fifth (82.4\%) of neonatal deaths occurred within the first week of life [2].

Ethiopia has developed and adopted national and international child health intervention strategies; including a national newborn and child survival strategy (2015-2020) to reduce NMR from 28 to $10 / 1000$ by 2020 [7, 8]. Also, Ethiopia has strived to achieve sustainable development goals (SDGs), aiming to reduce neonatal mortality to at least as low as 12 per 1000 live births by 203 0[34]. Despite this tremendous effort, the reduction of neonatal death is not promising to achieve the intended goal [34].

Risk factors for neonatal mortality such as place of residency, antenatal care (ANC) follow-up, and neonatal illness were indifferently explained by different authors $[4,11,13,14,21,24]$. So, identifying those factors will be important to guide the development of focused and evidence-based health interventions to reduce neonatal mortality. There is no clear evidence found to identify the magnitude of neonatal mortality and associated factors. Therefore, this study aimed at assessing the magnitude and factors associated with neonatal mortality among neonates admitted in a neonatal intensive care unit (NICU) at Hiwot Fana Specialized University Hospital (HFSUH), Harar, Eastern Ethiopia.

\section{Methods}

\section{Study setting and period}

This study was conducted at the neonatal intensive care unit of Hiwot Fana Specialized University Hospital, in Harar City. The city is located $517.2 \mathrm{~km}$ towards the east of Addis Ababa, the capital of Ethiopia. HFSUH currently provides different services for approximately 5.8 million people in the catchment area. The NICU is one of the Intensive Care Unit (ICU) services that the hospital is currently running. The hospital admits about 120 neonates per month on average and the unit is divided into a septic room, kangaroo mother care (KMC) room, and critical and subcritical rooms. The unit has 19 neonatal beds and $14 \mathrm{KMC}$ beds, 5 incubators, 10 radiant warmers, and 4 phototherapy machines. Additionally, there are 8 infusers, 4 oxygen cylinders, pulse oximetry, glucometer, and neonatal resuscitation equipment. The unit is staffed with 6 pediatricians, pediatric residents, 4 neonatal nurses, and 7 clinical nurses. The study had been conducted from February 20 to March 21, 2020.

\section{Study design and population}

A facility-based cross-sectional study design was conducted among 834 randomly selected neonates admitted to NICU of HFSUH. All neonates admitted to NICU of HFSUH from December 1, 2016, to December 31, 2019, were the study population. Neonates with incomplete medical records, neonates referred to other places, and left against medical advice were excluded from the study.

\section{Sampling size determination and sampling procedure}

The sample size was calculated by using a single population proportion formula with assumptions of confidence level at $95 \%=1.96$, a margin of error $(d)=0.03$, and a reasonable proportion of neonatal mortality $(P=0.23)$ from a previous study conducted at NICU of Gondar 
referral hospital [14] and adding 10\% non-retrieval rate, the final sample size became 834 . The total number of neonates admitted to NICU from December 1, 2016, to December 31, 2019, was 4204. The sampling frame was prepared for those study populations (admitted neonates) using their Medical Registration Number (MRN) obtained from their medical records. Finally, the study subjects that had been included in the study were identified by using a simple random sampling technique (computer-based) from the sampling frame $(N=4204)$.

\section{Data collection methods and quality assurance}

Data were extracted from medical records of newborns using a checklist adapted from the WHO document of review and audit of neonatal death [32] and registration book neonates. We used a pretested checklist containing four sections such as; socio-demographic characteristics related factors; the age of mother and residence; Antenatal related factors such as ANC visit, parity, and type of pregnancies; Neonatal related factors such as neonatal illness, gestational age, birth weight, sex of neonate, APGAR score, and length of stay; Intrapartum related factors such as delivery complications, place of delivery, and mode of delivery. The data were collected by welltrained 10 BSc nurses and supervised for quality of data extraction.

\section{Operational definitions}

Neonatal mortality is defined as the number of neonates who died at the neonatal intensive care unit throughout the study period [20]. Magnitude of neonatal mortality means that the proportion of neonatal death among neonates admitted to NICU.

Cause of neonatal death means that any medical or other causes diagnosed by pediatricians after conducting the necessary laboratory investigation and recorded on the medical chart as a cause of neonatal death.

Inadequate Antenatal visit means that having ANC follow-up $<4$ times [24].

Hypothermia: Any low body temperature measurement $\left(<36.5^{\circ} \mathrm{C}\right)$ was diagnosed and recorded on charts during the admission of neonates [17].

Prematurity is described as live-born neonates delivered before 37 completed weeks that are already diagnosed by professionals in charge of the admission of the neonate to neonatal intensive care units [4].

Sepsis: Record of infection or sepsis diagnosed either clinically or with culture by professionals during admission of the neonate and recorded on the chart [17].

Birth asphyxia: is diagnosed whenever a neonate had an Apgar score $<6$ in the fifth minute and/or if he/she did not cry immediately after birth; had respiratory distress, floppiness, loss of consciousness, presence of convulsion, and loss of neonatal reflexes [4].
Birth weight is classified using WHO weight classification, Low birth weight is any child with birth weight is less than $2500 \mathrm{~g}$ [30]. All other assessments are based on physician judgment as written in the patient card.

\section{Data processing and analysis}

The data were coded, edited, cleaned, and entered into Epi data statistical software version 3.1 and then exported to SPSS version 20 for analysis. A descriptive statistical analysis was used to summarize data. The information was presented using frequencies, tables, and figures. Neonatal mortality was categorized into died (coded 1) and survived (coded 0 ).

Bivariate analysis and multivariate analysis were done to observe the association between independent variables and the outcome variable by using binary logistic regression. All variables with $P \leq 0.25$ in the bivariate analysis were included in the final model of multivariate analysis to control all possible confounders. The model goodness of fit was tested by the Hosmer-Lemeshow statistic and Omnibus test. The model was considered a good fit since it is found to be insignificant for HosmerLemeshow statistic $(p=0.410)$ and significant for Omnibus tests $(p=0.000)$ The multi co-linearity test was carried out to observe the correlation between independent variables using VIF, and standard error, no variables were observed with VIF of $>10$ and standard error $>2$. The direction and strength of statistical association were measured by the odds ratio with $95 \%$ CI. The adjusted odds ratio (AOR) along with 95\% CI was estimated to identify factors for neonatal mortality by using multivariate analysis in the binary logistic regression. In this study $P$-value $<0.05$ was considered to declare a result as a statistically significant association.

\section{Result}

\section{Socio-demographic characteristics}

Out of 834 selected neonates, 2 neonates were referred to Black Lion Hospital, 5 neonates were left against medical advice and 6 neonates had incomplete medical records. A total of 821 neonates' outcome status was included in the analysis. Out of those, 534 (65\%) were from outside of Harar City. Four hundred forty-one (53.7\%) neonates were males. Maternal age was documented for 735 (89.5\%), of which 51 (6.9\%) of the mother were below age 19 and $77.9 \%$ of mothers were between 20 and 35 years old.

\section{Obstetrics characteristics}

More than three-fourth (75.2\%) of mothers had ANC follow-up. There were 47 (5.7\%) mothers with a history of neonatal death. The majority of 751 (91.5\%) mothers had a singleton pregnancy. Two hundred fifteen (26.2\%) mothers were experienced with obstetric complications 
during the current pregnancy. The most common complication was Antepartum Hemorrhage (APH) 81(37.7\%), followed by pregnancy-induced hypertension 79 (36.7\%), premature rupture of membrane (PROM) 47 (21.9\%), and preterm labor 29 (13.5\%). The majority of $698(85 \%)$ of the neonates were born at the hospital. More than half $(69.4 \%)$ of neonates were term while 247 $(30.1 \%)$ of neonates were preterm (Table 1$)$.

\section{Clinical characteristics of neonates at admission}

Four hundred eighty-five (59.1\%) of neonates were admitted within $24 \mathrm{~h}$ of life. The median age at admission was $8 \mathrm{~h}$ with an interquartile range of $71 \mathrm{~h}$. The majority of $660(80.4 \%)$ neonates stayed at the hospital for less than 7 days. The median hospital stay was $72 \mathrm{~h}$ with an interquartile range of $120 \mathrm{~h}$ (Table 2).

Concerning admission problems, more than half (53.5\%) of admissions were due to neonatal sepsis. Of those, 62 died, accounting for $52.5 \%$ of total neonatal mortality. On the other hand, hypothermia accounts for $312(38 \%)$ of admissions and accounts for $2.5 \%$ of neonatal deaths. Low birth weight was the third cause of admission to NICU, 282 (34.3\%), and 59 (50\%) of neonatal admissions and deaths respectively. There were 5 neonates exposed to HIV (Fig. 1).

\section{Magnitude of neonatal mortality}

From a total of 821 neonates admitted over 3 years, 118 neonatal deaths were recorded in the neonatal intensive care unit of Hiwot Fana Specialized University Hospital. Accordingly, the magnitude of neonatal mortality becomes 14.4\% (95\% CI:11.9,16.7). Neonatal sepsis, low birth weight, and prematurity were identified as the leading cause of neonatal mortality (Fig. 2).

\section{Factors associated with neonatal mortality}

Antepartum hemorrhage, pregnancy-induced hypertension, type of pregnancy, place of delivery, LBW, neonatal sepsis, and Perinatal Asphyxia (PNA) were significantly associated with neonatal mortality.

Multivariate analysis indicated that neonates born from mothers with current pregnancy complicated with antepartum hemorrhage $(\mathrm{APH})$ were 4.13 times [AOR = $4.13,95 \% \mathrm{CI}(1.92,8.85)]$ more likely to die as compared to neonates born from mothers without pregnancy complicated with APH. The odds of neonatal mortality increased by 4.41 times [AOR $=4.41,95 \% \mathrm{CI}$ : $(1.97,9.86)$ ] for neonates born from mothers with pregnancy complicated with pregnancy-induced hypertension, 2.87 times [AOR $=2.87,95 \% \mathrm{CI}(1.08,7.61)]$ for neonates born from mothers with multiple pregnancy, and 5.05 times $[\mathrm{AOR}=5.05,95 \% \mathrm{CI}:(1.72,14.79)]$ for neonates delivered at a health center.
Table 1 Obstetrics related characteristics of the mothers who gave birth to neonates admitted to HFSUH, Harar Ethiopia, 2020

\begin{tabular}{|c|c|c|}
\hline Variables & Frequency & Percentage \\
\hline \multicolumn{3}{|l|}{ ANC follow-up $(n=821)$} \\
\hline Yes & 617 & 75.2 \\
\hline No & 204 & 24.8 \\
\hline \multicolumn{3}{|c|}{ Number of ANC visit $(n=617)$} \\
\hline$\leq$ Three & 468 & 75.9 \\
\hline Four and above & 149 & 24.1 \\
\hline \multicolumn{3}{|l|}{ Parity $(n=821)$} \\
\hline Primiparous & 315 & 38.4 \\
\hline Multiparous & 388 & 47.3 \\
\hline Grand multiparous & 118 & 14.4 \\
\hline \multicolumn{3}{|c|}{ Type of pregnancy (number of gestations) $(n=821)$} \\
\hline Singleton & 751 & 91.5 \\
\hline Multiple & 70 & 8.5 \\
\hline \multicolumn{3}{|c|}{ History of neonatal loss $(n=821)$} \\
\hline Yes & 47 & 5.7 \\
\hline No & 774 & 94.3 \\
\hline \multicolumn{3}{|c|}{ Complication during pregnancy $(n=821)$} \\
\hline Yes & 215 & 26.2 \\
\hline No & 606 & 73.8 \\
\hline \multicolumn{3}{|c|}{ Place of delivery $(n=821)$} \\
\hline Home & 35 & 4.3 \\
\hline Health center & 88 & 10.7 \\
\hline Hospital & 698 & 85 \\
\hline \multicolumn{3}{|l|}{ Onset of labor $(n=821)$} \\
\hline Spontaneous & 742 & 90.4 \\
\hline Induced & 40 & 4.9 \\
\hline $\mathrm{C} / \mathrm{S}$ before onset & 39 & 4.8 \\
\hline \multicolumn{3}{|c|}{ Duration of labor $(n=821)$} \\
\hline$<24 \mathrm{~h}$ & 778 & 94.8 \\
\hline$\geq 24 \mathrm{~h}$ & 43 & 5.2 \\
\hline \multicolumn{3}{|c|}{ Mode of delivery $(n=821)$} \\
\hline SVD & 612 & 74.5 \\
\hline $\mathrm{C} / \mathrm{S}$ & 175 & 21.3 \\
\hline Instrumental & 34 & 4.2 \\
\hline \multicolumn{3}{|c|}{ Gestational age at delivery $(n=821)$} \\
\hline Preterm & 247 & 30.1 \\
\hline Term & 570 & 69.4 \\
\hline Post-term & 4 & 0.5 \\
\hline
\end{tabular}

The odds of death among newborns who had low birth weight were 4.01 times that of neonates who did not have the conditions $[\mathrm{AOR}=4.01,95 \% \mathrm{CI}(1.30,12.33)]$. Neonates with a diagnosis of perinatal asphyxia had 3.85 times higher odds of death compared to those neonates 
Table 2 Clinical characteristics of neonates admitted at HFSUH, Harar, Ethiopia, 2020

\begin{tabular}{lcl}
\hline Variable & Frequency & Percentage \\
\hline Age of neonate on admission $(n=821)$ & \\
$<24 \mathrm{~h}$ & 485 & 59.1 \\
$24-168 \mathrm{~h}$ & 208 & 25.3 \\
$\geq 168 \mathrm{~h}$ & 128 & 15.6 \\
Birth weight recorded $(n=716)$ & & 58.9 \\
Normal & 422 & 30.3 \\
LBW & 217 & 6 \\
VLBW & 43 & 0.3 \\
EVLBW & 2 & 4.5 \\
Macrosomia & 32 & \\
APGAR score on 1st minute $(n=674)$ & 19.1 \\
Low & 129 & 42.3 \\
Moderate & 285 & 38.6 \\
Normal/ reassuring & 260 & \\
APGAR score on 5th minute $(n=674)$ & 3.6 \\
Low & 24 & 29.4 \\
Moderate & 198 & 67.1 \\
Normal /reassuring & 452 & \\
Length of stay at hospital $(n=821)$ & 660 & \\
$<7$ days & 161 & \\
$\geq 7$ days & & \\
\hline
\end{tabular}

without perinatal asphyxia $[\mathrm{AOR}=3.85,95 \% \mathrm{CI}$ : $(1.83$, 8.10)]. The odds of death among neonates who had early neonatal sepsis were 3.93 times that of neonates who did not have the conditions [AOR $=3.93,95 \% \mathrm{CI}$ : (1.84, $8.41)$, and the odds of death who had late neonatal sepsis were 4.59 times that of neonates who did not have the conditions $[\mathrm{AOR}=4.59, \quad 95 \% \mathrm{CI}: \quad(1.09,19.25)]$ (Table 3).

\section{Discussion}

In this study, it was attempted to indicate the magnitude of neonatal mortality. Majority of the neonatal death are due to preventable and treatable causes. Neonatal deaths mainly due to poor maternal health, inadequate care during pregnancy, inappropriate management of complications during pregnancy and delivery, poor hygiene during delivery and the first critical hours after birth, and lack of newborn care. The researchers tried to isolate factors that influence neonatal death at a tertiary hospital in Ethiopia. Accordingly, it has been observed that APH, PIH, type of pregnancy, place of delivery, LBW, asphyxia, and neonatal sepsis were factors significantly associated with neonatal mortality at NICU.

Certain evidence indicates that most of the Ethiopian hospitals NICU is not well equipped and higher patient- to nurse ratio which exposes the neonates to different complications that in turn increase the chance of dying [18]. The overall proportion of neonatal mortality in this study is consistent with studies conducted in Bangladesh 14.9\% [22], Jimma 13.3\% [21], and Gondar referral hospital, northwest Ethiopia 14.3\% [4]. But the finding was lower compared to studies conducted in Ghana at 20.2\% [20], MizanTepi University Teaching Hospital, southwest Ethiopia 22.8\% [17], and Gondar referral hospital, northwest Ethiopia $23.1 \%$ [14]. This variation might be due to the lower sample size of the current study than studies $[17,20]$. Another possible justification is that home delivery $(10.1 \%)$ was high in Gondar compared to this study (4.3\%) [14]. This may expose the neonate to infection, intrapartum, and postpartum complications because home delivery does not take place in aseptic conditions that have a deleterious effect on maternal and neonatal health.

However, the magnitude of neonatal mortality was higher than studies conducted in Iran at 10.23\% [11], Cameroon at 10\% [16], and Eritrea at 6.6\% [1]. This discrepancy might be due to the health facility setups because some of the setups could be well-equipped, with the presence of skilled manpower. Another possible reason may be in this study about $26.2 \%$ of mothers of neonates had obstetrical complications during pregnancy compared to the study conducted in Eritrea (6.1\%) [1]. So, the neonates may suffer different problems like Intra Uterine Growth Restriction (IUGR), asphyxia from pregnancy complications which lead to neonatal mortality.

In this study, Neonates born from mothers with current pregnancy complicated with antepartum hemorrhage (APH) was 4.13 times more likely to die as compared to neonates born from mothers without pregnancy complicated with APH. In fact that, pregnancy complicated with APH leads to fetal hypoxia then which leads to fetal bradycardia and fetal death [3]. Such complications can be reduced through the provision of proper antenatal care during pregnancy. Systematic review and meta-analysis study conducted in Ethiopia showed that a mother who had ANC follow-up had a positive impact in reducing neonatal mortality due to different obstetrical complications [23]. This implies that neonatal mortality due to APH can be decreased by utilization of antenatal care services.

Also, the odds of neonatal mortality for those neonates born from mothers with current pregnancy complicated with pregnancy-induced hypertension was 4.41 times that of neonates born from mothers without current pregnancy complicated with pregnancy-induced hypertension. The possible reason is that pregnancy-induced hypertension leads to uteroplacental dysfunction which results in nutritional and oxygen supply to fetus deficiency and causing IUGR, preterm delivery, and low 


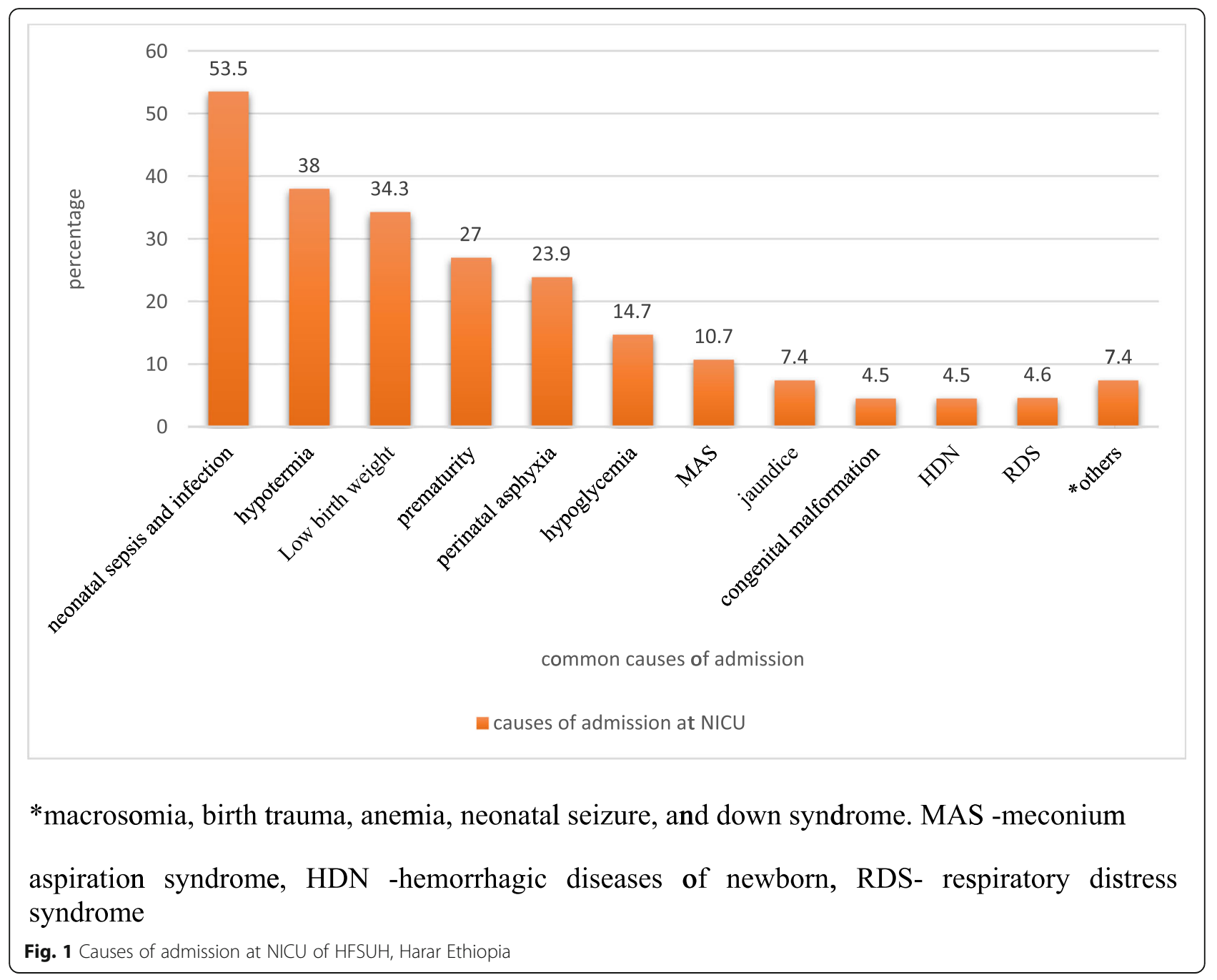

birth weight which results in neonatal death [3]. According to UNICEF report, majority of the neonatal deaths are easily preventable with effective interventions administered during pregnancy and childbirth [25]. However, there is a certain degree of variation in the provision of health care services for the mothers and their newborns. In turn, mothers are exposed to different obstetrical complications that result in deterioration of the life of the mothers and newborns.

In this study, Neonates born from mothers with multiple pregnancy were 2.87 times higher odds of neonatal mortality than those of singleton pregnancy. The possible justification is that multiple pregnancy causes preterm delivery IUGFR, congenital malformation, and LBW [3]. These complications lead to neonatal death.

The odds of neonatal mortality among neonates delivered at the health center were 5.05 times that of neonates delivered at hospitals. This is consistent with studies conducted in Nigeria and Mauritania
$[19,29]$. This may be due to the unavailability of skilled manpower and equipment to treat those sick neonates immediately after delivery in the health center.

The majority of neonatal deaths in low- and midincome countries are due to preventable and treatable conditions. A systematic review and meta-analysis done in Ethiopia show that most of the neonates died due to perinatal asphyxia, neonatal sepsis, prematurity problems, and birth injuries [23]. Health service utilization during pregnancy and child birth minimize neonatal death due to those preventable conditions, similarly in this study, the odds of death among newborns that had low birth weight were 4.01 times that of neonates who did not have the conditions. This is consistent with studies conducted in Brazil, GuineaBissau, Eritrea, Jimma, and eastern Ethiopia [1, 5, 9, 13, 21]. The possible justification is that in fact that low birth weight had immaturity of immune systems and, other body defense mechanisms that control 


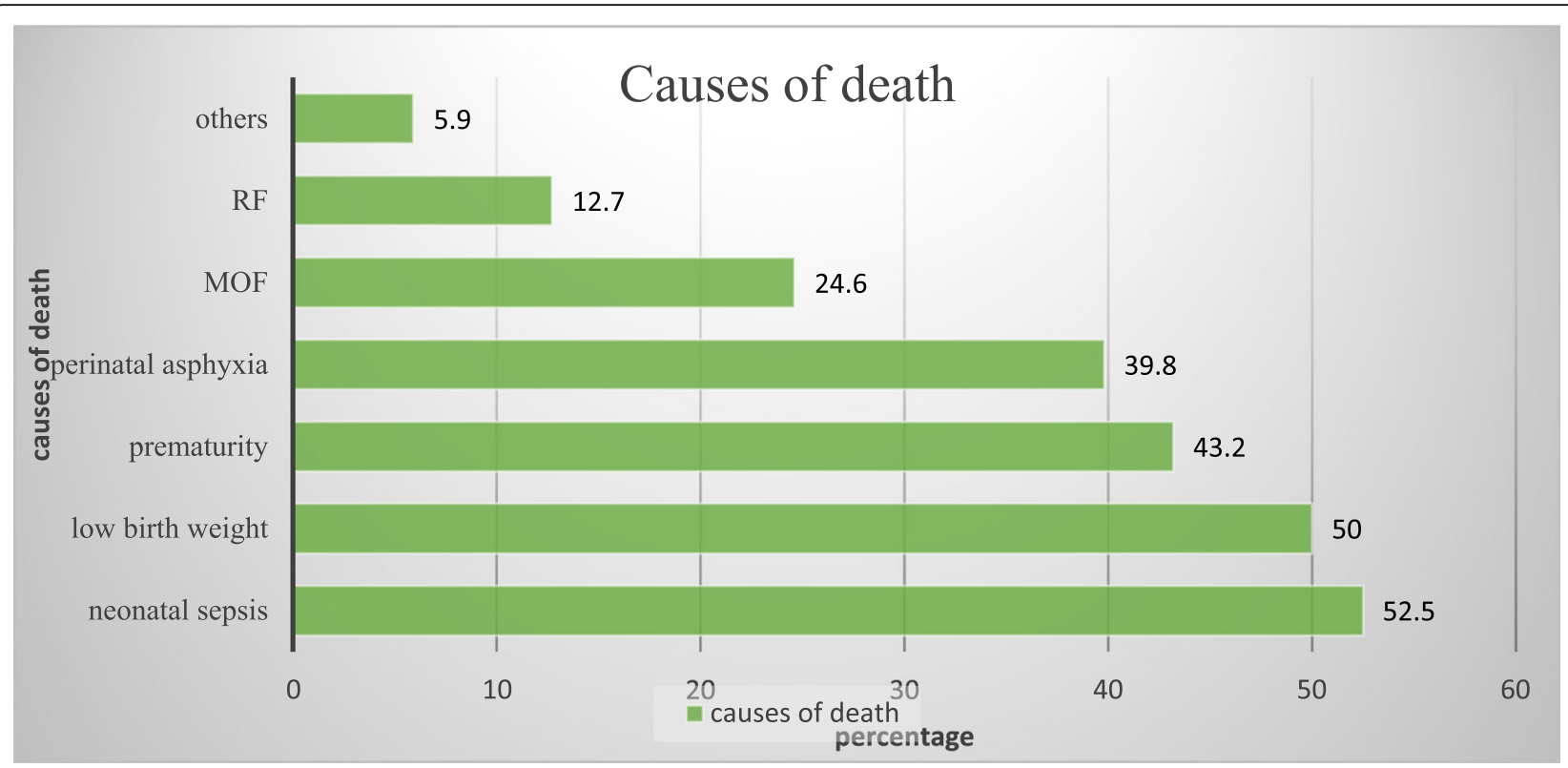

Others $=\mathrm{HDN}$, hypothermia, congenital malformation, MOF-multi-organ failure, RF-respiratory failure, HDN- hemorrhagic diseases of newborn

Fig. 2 The leading causes of neonatal mortality at HFSUH, Harar, Ethiopia

newborn disease susceptibility [15]. Then the neonates may develop health problems including RDS, bleeding from the brain, NEC, and finally, neonatal death may follow.

Similarly, neonates with a diagnosis of perinatal asphyxia had 3.85 times higher odds of death compared to those neonates without birth asphyxia. This is consistent with studies conducted in Ghana, Gondar, Mekele, and Jimma, Ethiopia $[4,10,14,20]$. The possible justification is that asphyxia causes carbon dioxide levels to increase and causing acidosis which leads to hypotension and ischemia then leads to brain cell injury then neonatal death [15].

Neonatal mortality remains an urgent concern of the country. A systematic review and meta-analysis conducted in Ethiopia showed that majority of the neonatal deaths that occur after delivery were due to neonatal sepsis because neonates are susceptible to infections and the progression of the disease are more rapid due to developmental immunodeficiency [36]. Similarly, in this study the odds of death among neonates who had early neonatal sepsis been 3.93 times that of neonates who did not have the conditions, and the odds of death which had late neonatal sepsis been 4.59 times that of neonates who did not have the conditions. This is consistent with studies conducted in Ghana, Gondar, and Mekele, Ethiopia $[4,10,14,20]$. The possible justification is that sepsis results in abscess formation, venous thrombosis, neurologic damage, and multi-organ dysfunction [35]. Finally, neonatal mortality may follow. The death of neonates due to neonatal sepsis can be minimized by the provision of proper postnatal care and proper health service at NICU [31]. Evidence showed that neonates who get proper care at NICU had a lower chance of death due to sepsis [36]. Strengthening the care provided at the post-natal period and NICU is very important in reducing neonatal mortality.

\section{Limitation of study}

The limitation of this study was it might not indicate a cause-effect relationship because the study design was cross-sectional. The use of medical records of newborns because of incompleteness and since the study is institution-based, the results might lack generalization to the entire population in the catchment area.

\section{Conclusion}

The study revealed that the overall proportion of neonatal mortality was relatively in line with other studies conducted in Ethiopia but still needs attention. This study identified that pregnancy complications during current pregnancy like $\mathrm{APH}$, and $\mathrm{PIH}$, type of pregnancy, place of delivery, LBW, having PNA, and having neonatal sepsis were the independent factors 
Table 3 Factors associated with neonatal mortality at Hiwot Fana Specialized University Hospital, Harar, Ethiopia, 2020

\begin{tabular}{|c|c|c|c|c|c|}
\hline \multirow[t]{2}{*}{ Variables } & & \multicolumn{2}{|c|}{ Neonatal mortality } & \multirow[t]{2}{*}{ COR $(95 \% \mathrm{CI})$} & \multirow[t]{2}{*}{ AOR $(95 \% \mathrm{Cl})$} \\
\hline & & Survived & Died & & \\
\hline \multirow[t]{2}{*}{ ANC follow-up } & Yes & 544 & 73 & 1 & 1 \\
\hline & No & 159 & 45 & $2.11(1.398,3.182) * *$ & $0.864(0.437,1.709)$ \\
\hline \multirow[t]{2}{*}{$\mathrm{APH}$} & No & 91 & 43 & 1 & 1 \\
\hline & Yes & 38 & 43 & $2.395(1.358,4.224) *$ & $4.126(1.923,8.853) * *$ \\
\hline \multirow[t]{2}{*}{$\mathrm{PIH}$} & No & 91 & 45 & 1 & 1 \\
\hline & Yes & 38 & 41 & $2.182(1.237,3.85) *$ & $4.406(1.969,9.861) * *$ \\
\hline \multirow[t]{2}{*}{ Type of pregnancy } & Single & 652 & 99 & 1 & 1 \\
\hline & Multiple & 51 & 19 & $2.454(1.391,4.328) *$ & $2.869(1.082,7.609) *$ \\
\hline \multirow[t]{3}{*}{ Place of delivery } & Hospital & 613 & 85 & 1 & 1 \\
\hline & Home & 21 & 14 & $4.8(2.356,9.811) * *$ & $3.475(0.719,16.804)$ \\
\hline & Health center & 69 & 19 & $1.986(1.139,3.46) *$ & $5.048(1.723,14.788) *$ \\
\hline \multirow[t]{2}{*}{ Prematurity } & No & 541 & 58 & 1 & 1 \\
\hline & Yes & 162 & 60 & $3.455(2.31,5.161) * *$ & $0.398(0.127,1.244)$ \\
\hline \multirow[t]{2}{*}{ Low birth weight } & No & 496 & 43 & 1 & 1 \\
\hline & Yes & 207 & 75 & $4.179(2.778,6.29) * *$ & $4.005(1.301,12.326) *$ \\
\hline \multirow[t]{3}{*}{ Sepsis } & No & 338 & 44 & 1 & 1 \\
\hline & Early-onset & 290 & 62 & $1.642(1.082,2.492) *$ & $3.931(1.837,8.412) * *$ \\
\hline & Late-onset & 75 & 12 & $1.229(0.619,2.440)$ & $4.587(1.093,19.252) *$ \\
\hline \multirow[t]{2}{*}{ Asphyxia } & No & 556 & 69 & 1 & 1 \\
\hline & Yes & 147 & 49 & $2.686(1.785,4.04) * *$ & $3.848(1.829,8.096) * *$ \\
\hline \multirow[t]{2}{*}{ Respiratory distress syndrome } & No & 680 & 103 & 1 & 1 \\
\hline & Yes & 23 & 15 & $4.306(2.175,8.52) * *$ & $1.662(0.566,4.875)$ \\
\hline
\end{tabular}

CI Confidence Interval, COR Crude Odds Ratio, AOR Adjusted Odds ratio, APH Antepartum Hemorrhage, MAS Meconium Aspiration Syndrome, RDS Respiratory Distress Syndrome

*Significant with $P<0.05$ and ** Significant with $P<0.001$

associated with neonatal mortality. Most of the neonatal deaths are due to preventable and treatable conditions. Health care providers, hospital management should work hard to improve care for all neonates with special attention to the care of high-risk neonates and should focus on factors that affect neonatal survival to reduce neonatal mortality.

\section{Abbreviations}

ANC: Antenatal care; APGAR: Appearance Pulse Grimace Activity Respiration; APH: Antepartum Hemorrhage; HFSUH: Hiwot Fana Specialized University Hospital; NICU: Neonatal Intensive Care Unit; NMR: Neonatal Mortality Rate; UNICEF: United Nations Children's Fund; WHO: World Health Organization

\section{Acknowledgments}

The author would like to thank Haramaya University, CHMS for giving the chance and support to perform this research thesis. I would like to thank my friends for their encouragement, insightful comments, and hard questions.

\section{Authors' contributions}

$A E$, the corresponding author, worked on designing the study, trained, and supervised the data collectors, checked the completeness of collected data, entered, analyzed, and interpreted the result, and prepared the manuscript. The co-authors namely MD, HS, TG, and GA played their role in re-analyzing and writing the final draft of the results. Moreover, the co-authors wrote the manuscript. All authors were involved in reading and approving the final manuscript.

\section{Funding}

Haramaya university.

\section{Availability of data and materials}

The data set generated or analyzed during the current study are not publicly available due to the privacy of the participants and institution restriction but are available from the corresponding author on reasonable request.

\section{Declarations}

Consent to publication

Non-applicable

Ethics approval and consent to participate

Ethical clearance was secured from Haramaya University, College of Health and Medical Sciences, Institutional Health Research Ethics Review Committee (IHRERC). Informed, voluntary, written and signed consent was obtained from hospital administrators before the data collection.

Since the study was based on secondary data there was no direct contact with patients. So, anonymity was maintained by using the identified number instead of the patient's names. Besides, all data extracted were kept confidential and not used for any other purpose than the stated objective and all methods were carried out per ethical guidelines.

Competing interests

There is no conflict of interest. 


\section{Author details}

'Department of Midwifery, School of Nursing and Midwifery, College of Health and Medical Sciences, Haramaya University, P.O. BOX 138, Dire Dawa, Harar, Ethiopia. ${ }^{2}$ Department of Epidemiology, School of Public Health, College of Health and Medical Sciences, Haramaya University, Harar, Ethiopia. ${ }^{3}$ Department of Pediatrics, School of Nursing and Midwifery, College of Health and Medical Sciences, Haramaya University, Harar, Ethiopia. ${ }^{4}$ School of Nursing and Midwifery, College of Health and Medical Sciences, Haramaya University, Harar, Ethiopia.

Received: 9 November 2020 Accepted: 4 March 2021 Published online: 15 March 2021

\section{References}

1. Andegiorgish AK, Andemariam M, Temesghen S, Ogbai L, Ogbe Z, Zeng L. Neonatal mortality and associated factors in the specialized neonatal care unit Asmara, Eritrea. BMC Public Health. 2020;20(1):10. https://doi.org/10.11 86/s12889-019-8118-X

2. Assefa N, Oljira L, Belay B, Kedir H, Ashenafi W, Dedefo M, et al. Neonatal mortality and causes of death in Kersa Health and Demographic Surveillance System (Kersa HDSS), Ethiopia, 2008-2013. Matern Health Neonatol Perinatol. 2016;2(1):7. https://doi.org/10.1186/s40748-016-0035-8.

3. Cunningham FG, Leveno KJ, Bloom SL, Spong CY, Dashe JS, Hoffman BL, Casey BM, Sheffield JS. Williams obstetrics. 24th ed; 2014

4. Demisse AG, Alemu F, Gizaw MA, Tigabu Z. Patterns of admission and factors associated with neonatal mortality among neonates admitted to the neonatal intensive care unit of University of Gondar Hospital, Northwest Ethiopia. Pediatric Health Med Ther. 2017:8:57-64. https://doi.org/10.2147/ PHMT.S130309.

5. Desalew A, Sintayehu Y, Teferi N, Amare F, Geda B, Worku T, Abera K, Asefaw A. Cause and predictors of neonatal mortality among neonates admitted to neonatal intensive care units of public hospitals in eastern Ethiopia: a facility-based prospective follow-up study. BMC Pediatr. 2020; 20(1):160. https://doi.org/10.1186/s12887-020-02051-7.

6. Ephi EPHI, Icf. Ethiopia mini demographic and health survey 2019: key indicators. Rockville: EPHI and ICF; 2019.

7. Fmoh. National newborn and child survival strategy document brief summary 2015/16-2019/20. 2015. https://searchworks.stanford.edu/view/11 932265 .

8. Fmoh. Health sector transformation plan-i annual performance report; 2017. https://doi.org/10.1080/21665095.2018.1543549.

9. Gaiva M a M, Fujimori E, Sato APS. Maternal and child risk factors associated with neonatal mortality. Texto Contexto Enferm. 2016;25

10. Hadgu FB, Gebretsadik LG, Mihretu HG, Berhe AH. Prevalence and factors associated with neonatal mortality at Ayder comprehensive specialized hospital, northern Ethiopia. A cross-sectional study. Pediatric Health Med Therapeutics. 2020;11:29-37.

11. Hoseini BL, Sadati ZMK, Rakhshani MH. Assessment of neonatal mortality in the neonatal intensive care unit in Sabzevar City for the period of 20062013. Electron Physician. 2015;7(7):1494-9. https://doi.org/10.19082/1494.

12. Hug L, Alexander M, You D, Alkema L. National, regional, and global levels and trends in neonatal mortality between 1990 and 2017, with scenariobased projections to 2030: a systematic analysis. Lancet Glob Health. 2019; 7(6):e710-20. https://doi.org/10.1016/S2214-109X(19)30163-9.

13. Joergensen ASP, Bjerregaard-Andersena M, Biering-Sørensen S, Byberg S, Camala L, Martins C, et al. Admission and mortality at the main neonatal intensive care unit in Guinea-Bissau. Trans R Soc Trop Med Hyg. 2018:0:1-7.

14. Kokeb M, Desta T. Institution based prospective cross-sectional study on patterns of neonatal morbidity at Gondar University Hospital Neonatal Unit, North-West Ethiopia. Ethiop J Health Sci. 2016;26(1):73-9. https://doi.org/1 0.4314/ejhs.v26i1.12

15. Kliegman MR, Stanton FB, W J. \& F N. Nelson textbook of pediatrics edition, vol. 20; 2016. https://doi.org/10.1016/B978-1-4557-7566-8.00729-8

16. Mah ME, Chiabi A, Tchokoteu PF, Nguefack S, Bogne J, Siyou H, et al. Neonatal mortality in a referral hospital in Cameroon over a seven year period: trends, associated factors and causes. Afr Health Sci. 2014;14(3):51725. https://doi.org/10.4314/ahs.v14i3.4.

17. Mekonnen T, Tenu T, Aklilu T, Abera T. Assessment of neonatal death and causes among admitted neonates in Neonatal Intensive Care Unit of Mizan Tepi University Teaching Hospital, Bench Maji Zone, South-West Ethiopia, 2018. Clin Mother Child Health. 2018;15.
18. Mekonnen W, Desalegn A. Quality of service and associated factors in neonatal intensive care unit at Debre Berhan referral hospital, Debre Berhan Ethiopia: A cross sectional study. Med J Dr. D.Y. Patil Vidyapeeth. 2018;11: 412.

19. Okposio MM, Ighosewe Ol. Morbidity and mortality pattern among neonates admitted to the general paediatric ward of a secondary health care centre in the Niger delta region of Nigeria. Sri Lanka J Child Health 2016;45(2):84. https://doi.org/10.4038/sljch.v45i2.7981.

20. Owusu BA, Lim A, Makaje N, Wobil P, Sameae A. Neonatal mortality at the neonatal unit: the situation at a teaching hospital in Ghana. Afr Health Sci. 2018;18(2):369-77. https://doi.org/10.4314/ahs.v18i2.22

21. Seid SS, Ibro SA, Ahmed AA, Olani AA, Reta EY, Haso TK, Fata GA. Causes and factors associated with neonatal mortality in Neonatal Intensive Care Unit (NICU) of Jimma University Medical Center, Jimma, South West Ethiopia. Pediatric Health Med Ther. 2019;10:39-48. https://doi.org/10.2147/ PHMT.S197280,

22. Shahidullah M, Hasan MZ, Jahan I, Ahmed F, Dey AC, Dey SK, Mannan M. Perinatal characteristics and outcome of neonates at NICU of a tertiary level hospital in Bangladesh. Bangladesh J Child Health. 2017;41:34-9.

23. Tekelab T, Chojenta C, Smith R, Loxton D. The impact of antenatal care on neonatal mortality in sub-Saharan Africa: A systematic review and metaanalysis. PLoS One. 2019;14(9):e0222566. https://doi.org/10.1371/journal. pone.0222566

24. Tewabe T, Mehariw Y, Negatie E, Yibeltal B. Neonatal mortality in the case of Felege Hiwot referral hospital, Bahir Dar, Amhara regional state, north West Ethiopia 2016: a one year retrospective chart review. Ital J Pediatr. 2018;44(1):57. https://doi.org/10.1186/s13052-018-0498-5.

25. Unicef. Committing to child survival: a promise renewed progress report 2013. 2013. https://www.unicef.org/publications/files/APR_Progress_ Report_2013_9_Sept_2013.pdf.

26. Unicef. Ethiopia maternal and newborn health disparities. 2015. https:// www.medbox.org/ethiopia/maternal-and-newborn-health-disparitiesethiopia-key-facts/preview?q=.

27. Unicef. Levels \& trends in report 2018 mortality estimates developed by the Un Inter-Agency Group For Child Mortality Estimation (UN IGME). 2018. https://www.un.org/en/development/desa/population/publications/morta lity/child-mortality-report-2018.asp.

28. Unicef, Who, Bank W. \& Unpd. Levels \& trends in child mortality report 2019 estimates developed by the UN inter-agency group for child mortality estimation. 2019. https://data.unicef.org/wp-content/uploads/2019/09/UNIGME-Child-Mortality-Report-2019.pdf.

29. Weddih A, Lemine M, Ahmed CB, Sidat M, Abdelghader N, Abdelghader F, et al. Prevalence and factors associated with neonatal mortality among neonates hospitalized at the National Hospital Nouakchott, Mauritania. Pan African Med J. 2019. https://doi.org/10.11604/pamj.2019.34.152.14683.

30. Who. Promoting optimal fetal development report of a technical consultation. 2010.

31. Who. WHO recommendations on postnatal care of the mother and newborn. 2013. https://apps.who.int/iris/bitstream/handle/10665/97603/ 9789241506649_eng.pdf;jsessionid=7B45AE94649B5DDA983C40DC22 8 B5EC6? sequence $=1$.

32. Who. Making Every Baby Count Audit and review of stillbirths and neonatal deaths. 2016a. https://www.who.int/maternal_child_adolescent/documents/ stillbirth-neonatal-death-review/en/.

33. Who. Neonatal and perinatal mortality: country, regional and global estimates. 2016b. https://www.who.int/reproductivehealth/publications/ma ternal_perinatal_health/monitoring/en/.

34. Who. Progress towards the SDGs: A selection of data from World Health Statistics 2018. 2018. https://www.who.int/sdg/en/.

35. Wynn JL, Wong HR. Pathophysiology of neonatal Sepsis. Clin Perinatol Elsiever. 2010;37:439-79.

36. Zaidi AKM, Ganatra HA, Syed S, Cousens S, Lee ACC, Black R, Bhutta ZA, Lawn JE. Effect of case management on neonatal mortality due to sepsis and pneumonia. BMC Public Health. 2011;11(Suppl 3):S13. https://doi.org/1 0.1186/1471-2458-11-S3-S13.

\section{Publisher's Note}

Springer Nature remains neutral with regard to jurisdictional claims in published maps and institutional affiliations. 